\title{
Shoulder Rotational Strength Profiles of Danish National Level Badminton Players
}

Martin B Stausholm, MSc, PT ${ }^{1}$, Martin Baun, $\mathrm{PT}^{2}$, Jan M Bjordal, PT, PhD ${ }^{3}$, Dorte Nielsen, DPT ${ }^{2}$, Henrik Aagaard, MD ${ }^{4}, \mathrm{~S}$ Peter Magnusson, PT, DSc ${ }^{5}$ Christian Couppé, MSc, PT, $\mathrm{PhD}^{5}$ a

1 Department of Global Public Health and Primary Care, University of Bergen; Department of Physical Therapy, Bispebjerg Hospital, 2 Team Danmark,

3 Department of Global Public Health and Primary Care, University of Bergen, 4 Team Danmark; Department of Orthopaedic Surgery, Zealand University Hospital, 5 Department of Physical Therapy, Bispebjerg Hospital; Institute of Sports Medicine Copenhagen, Bispebjerg Hospital

Keywords: shoulder, overhead athletes, dynamometer, badminton, age

https://doi.org/10.26603/001c.21531

\section{International Journal of Sports Physical Therapy}

Vol. 16, Issue 2, 2021

\section{Background}

Increased age has been shown to be associated with weaker external rotators and stronger internal rotators of the shoulder in pitchers and tennis players. Whether this age-associated change is present in elite badminton players is unknown.

\section{Purpose}

To compare the internal and external rotation strength of the shoulder in adolescent and adult elite badminton players.

\section{Study design}

Cross-sectional.

\section{Methods}

Thirty-one adolescent (12 females aged $16.8 \pm 1.6$ years and 19 males aged $17.1 \pm 1.6$ years) and 29 adult (10 females aged $25 \pm 2.9$ years and 19 males aged $26.2 \pm 4.6$ years) national level badminton players were tested pre-seasonally for external rotation (ER) and internal rotation (IR) isometric muscle strength bilaterally, using a hand-held dynamometer. Within-group ER to IR strength ratios were calculated (ER/IR×100\%).

\section{Results}

The adolescents had stronger shoulder ER than the adults on both sides $(p<0.05)$. The adult males tended to have stronger IR of the dominant shoulder than the adolescent males $(\mathrm{p}=0.071)$. In the dominant shoulders, the strength ratios for adult females and males were $77 \%$ and $78 \%$, respectively, while the same ratio for adolescent females and males were $85 \%$ and $99 \%$, respectively. In the non-dominant shoulders, the ER/IR strength ratios for adult females and males were $90 \%$ and $87 \%$, respectively, while the ratios for adolescent females and males were $116 \%$ and $102 \%$, respectively.

\section{Conclusion}

This study is the first to demonstrate that in shoulder injury-free national team badminton players, adolescents have stronger shoulder ER than adults on both sides. Therefore, increased age appears to be associated with weaker shoulder ER muscles in elite badminton players.

\section{Level of evidence}

3b.

\footnotetext{
a Corresponding Author:

Christian Couppé, Department of Physical Therapy and Institute of Sports Medicine Copenhagen - IOC Research Center Copenhagen, Bispebjerg Hospital, Copenhagen, Denmark

Email: Christian.Couppe@regionh.dk
} 


\section{INTRODUCTION}

Shoulder injuries are common in upper extremity sports, particularly at the elite level. ${ }^{1-5}$ Many badminton players with shoulder pain continue their sport despite the risk of developing chronic conditions, such as subacromial pain syndrome and rotator cuff tendinopathy. ${ }^{1,6}$ Thus, knowledge of shoulder profiles of upper extremity athletes is of great value in an injury preventive perspective.

In various upper extremity sports (baseball pitching, swimming, tennis and golf), the overhead throwing type motion is somewhat similar according to studies of motion and electromyography. ${ }^{7-9}$ During the act of throwing, the eccentric forces/loads generated put excessive mechanical stress (load divided by tissue cross-sectional area) on the rotator cuff tendons and muscles, the capsule and the ligamentous structures of the shoulder, ${ }^{10}$ and these repetitive high loads may lead to overuse tendon injuries. ${ }^{11}$ It has been suggested that shoulder pathology in overhead sports is associated with external rotation (ER) muscle weakness ${ }^{12-14}$ and imbalance in the ratio between ER to internal rotation (IR) strength. ${ }^{15-17}$ Several authors have demonstrated ER muscle weakness of the dominant (DOM) shoulder compared to the non-dominant (NDOM) shoulder in high school and professional throwers ${ }^{18,19}$ and other overhead athletes. 20

The rotational shoulder strength of badminton players has only been minimally studied. $\mathrm{Ng}$ and Lam examined recreational badminton players and observed that male players have lower ER to IR strength of the DOM shoulder compared to the NDOM shoulder. ${ }^{21}$ In young elite badminton players, the rotational strength appears to be similar between the DOM and NDOM shoulders in the males, while there was a greater IR strength on the DOM side that was not balanced by a greater ER strength in females. ${ }^{17}$ The shoulder rotational strength profiles of shoulder injury-free adolescent and adult national level badminton players has not been compared previously.

Increased age has been associated with decreased shoulder strength, including of the internal and external rotators, in the more general population in the age range 20 to 39 years. ${ }^{22}$ It is possible that testosterone, which peaks at the average age of 19 and 17 years in males and females, respectively, and subsequently declines, explain these observations. ${ }^{23,24}$ Therefore, the present study was conducted to compare the ER and IR strength of the shoulder in adolescent and adult elite badminton players. It was hypothesized that compared to adult badminton players, adolescent badminton players have stronger shoulder ER and IR.

\section{METHODS}

\section{PARTICIPANTS}

Thirty-one adolescents; 12 females aged $16.8 \pm 1.6$ years and 19 males aged $17.1 \pm 1.6$ years, and 29 adults; 10 females aged $25 \pm 2.9$ years and 19 males aged $26.2 \pm 4.6$ years (mean \pm standard deviation) from the Danish national badminton team volunteered and participated in this cross-sectional study as part of a pre-season screening in 2005. Subject consent was given in accordance with the policy statements of American College of Sports Medicine and the Danish Society of Sports Medicine. The complete methods are described elsewhere. ${ }^{17}$

The players underwent a screening for injuries and were only allowed to participate in the study if they were free from any current and previous shoulder injury. This screening included an evaluation of the spine and shoulders, including the Hawkins-Kennedy test, Jobe's test, Apprehension test, O'Brien's test and foraminal compression/ distraction test. ${ }^{25,26}$ One adolescent female player was excluded due to joint instability of the NDOM shoulder.

\section{ASSESSMENTS}

The strength measurements were performed with a handheld dynamometer (HHD) (J-Tech Power Track ${ }^{\circledR}$ dynamometer, JTECH Medical, Salt Lake City, UT, USA) in the same test position as used in other studies. ${ }^{27,28}$ Shoulder ER and IR strength assessments were conducted with the participants lying in supine position with the shoulder abducted $90^{\circ}$ and in the scapular plane. ${ }^{27,29}$ The participants' elbows were flexed $90^{\circ}$ and the examiner stabilized the upper arm by pressing it down toward the examination table. The participants grasped the table with their non-testing arm, thereby providing additional stabilization. This position was selected due to its similarity with the badminton smash, to obtain maximum strength values and minimize risk of shoulder injury. ${ }^{30}$ The testing angle was checked visually. In the ER test, the participants externally rotated their shoulder against the HHD, while the HHD was located proximal to the ulnar styloid process. In the IR test, the participants internally rotated their shoulder against the HHD, while the HHD was located proximal to the ulnar styloid process. In both the ER and IR tests, the glenohumeral rotation was placed at midrange/neutral position, so the forearm was elevated to a vertical position. ${ }^{17}$ These were isometric "make tests" consisting of a 5-6 s maximum voluntary contraction (MVC) by the player. The "make test" is isometric in nature and therefore associated with less risk of muscle damage or soreness compared with the "break test". The specific HHD can register $0-500 \mathrm{~N}$ with a sensitivity of $0.2 \mathrm{~N}$ and it was calibrated prior to each trial. Two examiners tested the players blinded to side dominance, and for practical reasons, one examiner tested the adolescent group and another examiner tested the adult group. Intertester-reliability was thus evaluated. The player warmed up by performing 15 repetitions of ER and IR with a $1 \mathrm{~kg}$ dumbbell in side lying prior to the strength assessments, without becoming fatigued. The players were instructed in a standardized manner only to move their testing arm during the assessments. Prior to the trials, the players were reminded in a standardized manner of the importance of providing their MVC. A standardized verbal encouragement was given during each effort. A mean of three MVCs was recorded for IR and ER each. A 20-30 s pause was mandatory between each trial. ${ }^{22}$ The order of assessments was constant, i.e., right ER, right IR, left ER and left IR. ${ }^{31}$ Torque was calculated as strength $(\mathrm{N}) ¥$ full arm length $(\mathrm{m})$ and normalized to body weight $(\mathrm{N} \mathrm{m} / \mathrm{kg})$. Full arm length was measured just proximal to the ulnar styloid process and just below to the acromion. ${ }^{17}$ 
Table 1: Participants’ age, arm length and body weight. Values are mean \pm standard deviation.

\begin{tabular}{|l|l|l|l|l|}
\hline & \multicolumn{2}{|c|}{ Females } & \multicolumn{2}{c|}{ Males } \\
\hline & Adolescents & Adults & Adolescents & Adults \\
\hline Number of players & 12 & 10 & 19 & 19 \\
\hline Age (years) & $16.8 \pm 1.6$ & $25.0 \pm 2.9$ & $17.1 \pm 1.6$ & $26.2 \pm 4.6$ \\
\hline Arm length $(\mathrm{m})$ & $0.54 \pm 0.04$ & $0.55 \pm 0.03$ & $0.60 \pm 0.03$ & $0.60 \pm 0.03$ \\
\hline Body weight $(\mathrm{kg})$ & $61.1 \pm 7.0\left(^{*}\right)$ & $65.0 \pm 6.3$ & $74.2 \pm 7.4(\dagger)$ & $78.4 \pm 5.9$ \\
\hline
\end{tabular}

Female adolescents versus female adults: $(*) \mathrm{p}=0.139$

Male adolescents versus male adults: $(\dagger) \mathrm{p}=0.065$

The selected test position has proven sensitive to detecting side-to-side differences. ${ }^{21,27}$ The HHD assessment is valid $^{29}$ and has shown to be more precise ${ }^{32}$ and sensitive ${ }^{33}$ to ER muscle weakness in the same test position when compared to an isokinetic strength test instrument. Also, assessment with HHD has proven to be intra- and inter-rater reliable. ${ }^{27,34}$

\section{STATISTICAL ANALYSIS}

Within- and between-group statistical comparisons were made with Wilcoxon's rank-sum test and Mann-Whitney $U$-test, respectively, since the data by visual inspection appeared not to be normally distributed. p-values of $<0.05$ were considered to be statistically significant. Within-group ER to IR strength ratios were calculated using the formula $\mathrm{ER} / \mathrm{IR} \times 100 \%$. Intra- and inter-rater reliability of the strength measurements were calculated and reported as typical error. ${ }^{35}$ All statistical analyses were performed using the software package GraphPad Prism ${ }^{\circledR} 6.0$ (San Diego, CA, USA).

\section{RESULTS}

\section{INTRA- AND INTER-RATER RELIABILITY}

For adolescents, the intra-rater reliability of the measurements was substantial with a typical error in percentage for IR and ER strength assessments of 5.4\% (3.9-6.9\%) and 5.4\% (5.3-6.8\%), respectively. The typical error in percentage for the IR and ER strength assessments of the adults was $4.6 \%$ (2.9-5.3\%) and 4.8\% (3.9-5.5\%), respectively. A Spearman's rank correlation coefficient (r) value was calculated to determine the strength of the relationship between the two highest values. The r-value was 0.99 . There were no systematic differences (paired t-test) between the two highest values. Inter-rater reliability on seven participants demonstrated a typical error in percentage for IR strength measurements of $6.8 \%$ and for ER strength measurements of $6.2 \%$. There were no significant differences between the two examiners in any of the testing movements.

\section{BODYWEIGHT AND ARM LENGTH OF THE GENDER AND AGE GROUPS}

The body weight and arm length of the gender and age

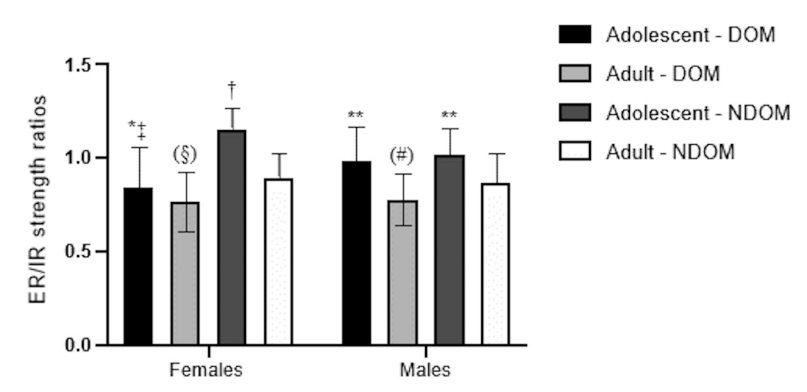

Figure 1: External/internal rotational shoulder strength ratios. Values are presented as mean (SD). ER: External rotation, IR: Internal rotation, DOM: Dominant shoulder, NDOM: Non-dominant shoulder

Female adolescents versus female adults: $* \mathrm{p}<0.05 ; \uparrow \mathrm{p}<0.01$

Male adolescents versus male adults: $* * 0<0.01$

Dominant versus non-dominant side: (§) $p=0.065$; (\#) $p=0.061 ; \ddagger p<0.05$

groups are presented in Table 1.

\section{EXTERNAL AND INTERNAL ROTATIONAL SHOULDER STRENGTH}

The males were generally stronger than the females. The adolescents had stronger shoulder ER than the adults ( $p$ $<0.05$ ). The adolescent and adult females and the adult males had stronger IR of the DOM shoulder compared to the NDOM shoulder $(\mathrm{p}<0.05)$. Expressed as a percentage, the adolescent females and males had 25\% and 13\% stronger DOM and $27 \%$ and $15 \%$ stronger NDOM shoulder ER than the adult females and males, respectively (Table 2). The adult males tended to have $12 \%$ stronger IR of the dominant (DOM) shoulder than the adolescent males, although this was not statistically different $(p=0.071)$ (Table 2). In the DOM shoulders, the ER/IR strength ratios for adult females and males were $77 \%$ and $78 \%$, respectively, while the ratios for adolescent females and males were $85 \%$ and $99 \%$, respectively. In the NDOM shoulders, the ER/IR strength ratios for adult females and males were $90 \%$ and $87 \%$, respectively, while the ratios for adolescent females and males were $116 \%$ and $102 \%$, respectively (Table 2 and Figure 1 ). 
Table 2: The badminton players shoulder torque normalized to $\mathrm{Nm} / \mathrm{kg}$. Values are mean \pm standard deviation.

\begin{tabular}{|l|l|l|l|l|}
\hline & \multicolumn{2}{|c|}{ Females } & \multicolumn{2}{c|}{ Males } \\
\hline & Adolescents & Adults & Adolescents & Adults \\
\hline ER DOM & $1.11 \pm 0.5 \dagger(\dagger \dagger)$ & $0.89 \pm 0.19$ & $1.39 \pm 0.20 \S$ & $1.23 \pm 0.31$ \\
\hline ER NDOM & $1.19 \pm 0.19 \dagger$ & $0.94 \pm 0.13$ & $1.44 \pm 0.28 \S$ & $1.25 \pm 0.31$ \\
\hline IR DOM & $1.31 \pm 0.31 \S \S$ & $1.16 \pm 0.20 \S \S$ & $1.40 \pm 0.30(\ddagger)$ & $1.57 \pm 0.30 \S \S$ \\
\hline IR NDOM & $1.03 \pm 0.19$ & $1.05 \pm 0.18$ & $1.37 \pm 0.26$ & $1.44 \pm 0.20$ \\
\hline ER/IR ratio DOM & $0.85 \pm 0.21^{*} \S \S$ & $0.77 \pm 0.16(\#)$ & $0.99 \pm 0.18^{* *}$ & $0.78 \pm 0.14(\neq \ddagger)$ \\
\hline ER/IR ratio NDOM & $1.16 \pm 0.11 \dagger$ & $0.90 \pm 0.13$ & $1.02 \pm 0.14^{* *}$ & $0.87 \pm 0.16$ \\
\hline
\end{tabular}

ER: External rotation, IR: Internal rotation, DOM: Dominant shoulder, NDOM: Non-dominant shoulder

Female adolescents versus female adults: ${ }^{*} \mathrm{p}<0.05 ; \dagger \mathrm{p}<0.01$

Male adolescents versus male adults: $(\ddagger) p=0.071 ; \S p<0.05 ; * * p<0.01$

Dominant versus non-dominant side: $(\dagger \dagger) p=0.067$; (\#) $p=0.065$; (市) $p=0.061 ; \S \S p<0.05$

\section{DISCUSSION}

The objective of this study was to describe and compare the shoulder rotational strength of adolescent and adult elite badminton players. The main findings were that the adolescent players had stronger shoulder external rotation (ER) than the adult players on both sides. These first data suggest that advanced age is associated with weaker shoulder ER in elite adult badminton players, which may warrant strengthening of the ER muscles as a player ages, which could be a potential strategy to reduce the risk of future shoulder injury.

\section{BADMINTON INDUCED ADAPTATIONS}

The badminton smash and the adaptations to the shoulder muscles are similar in other extremity sports involving the throwing motion. ${ }^{7,36}$ As mentioned, the adolescents in the present study were stronger than the adults, in terms of shoulder ER of both sides. Furthermore, the adult females and males had ER/IR strength ratios of $77 \%$ and $78 \%$ of the DOM shoulder, respectively, while the ratios were considerably more balanced (closer to 1:1) in the adolescent groups. These results are consistent with those of elite tennis players in the age of 10 -20 years. ${ }^{37}$

The stronger shoulder ER of the adolescent groups could be age-associated as observed in the more general population, where ER strength of both shoulders typically decreases during the adult life $22,31,38$ and/or as a consequence of possible overuse in the ER muscles-tendons due to the enormous demand for eccentric deceleration in the IR smashing motion. Of note, the results of the present study could also be influenced by different training behaviors (e.g., training type, intensity and frequency) in the different age and gender groups. The strength and power of the IR muscles may increase as an adaptation to the smashing motion. One function of the ER muscles is to decelerate the arm in throwing of follow through; they do not increase their strength proportionally like the IR muscles, probably due to the size of muscle-tendon structure. The ER rotator cuff muscle-tendons are smaller than the IR rotator cuff muscles-tendons, which could explain why some shoulder injuries occur from repetitive smashing and throwing.

It should be noted that, while weak ER strength was associated with higher risk of shoulder injury in a cohort study of 144 baseball pitchers $(\mathrm{p}=0.003)^{12}$ and in a cohort of 206 elite male handball players (odds ratio $=1.29$ ), ${ }^{13}$ such relation was not confirmed in a cohort of 329 elite handball players (odds ratio $=1.05) .{ }^{14}$

\section{GENDER DIFFERENCES}

As expected, in the present study, the males were stronger than the females after adjustment for body weight, and this can be explained by the physical sex difference. The results of the female age groups should be interpreted with caution, as the analyses may lack statistical power due to the relatively small sample sizes. Notably, Fahlstrom et al. observed that in world class badminton players, females generally perform less shoulder training than males. ${ }^{1}$ Thus, it was hypothesized that the same was evident in the current study and that it would be reflected in the results. However, based on the present data, it can be hypothesized that preventive strength training with proper restitution to stabilize and balance the rotator cuff is even more important in females than in males to reduce the risk of overuse injury in the shoulder. ${ }^{39,40}$

\section{ADDITIONAL CONSIDERATIONS AND LIMITATIONS}

This study has some limitations worth mentioning. It is cross-sectional in design and had a relatively small sample size, which prohibits conclusions about causality between shoulder rotational strength and aging with badminton play; future studies should be prospective in design and risk of injury should be correlated with shoulder strength.

Furthermore, shoulder strength was only tested isometrically, however, measuring eccentric strength would have provided more valid results. ${ }^{5,16,33}$ Also, the moment arm was measured just proximal to the ulnar styloid process and just below the acromion (full arm length) instead of the forearm length, thereby likely overestimating ER and IR torque. ${ }^{17}$

The number of hours played was not recorded and this may be a confounding factor; by recording hours played, 
it may be possible to separate badminton specific muscle strength/weakness adaptations from general aging factors. It is plausible that hours played is associated with weaker ER and stronger IR of the DOM shoulder due to repeated forceful internal rotational movements that may leave the smaller external rotators vulnerable to large eccentric forces.

\section{CONCLUSION}

This study is the first to demonstrate that in injury-free national team badminton players, adolescent players have greater isometric shoulder ER strength than adult players on both sides. It is plausible that increased age is associated with weaker shoulder ER in elite badminton players.

\section{FUNDING}

No outside funding was received for this work.

\section{CONFLICTS OF INTEREST}

The authors have no conflicts of interest to disclose.

Submitted: May 06, 2020 CDT, Accepted: November 08, 2020

CDT 


\section{REFERENCES}

1. Fahlstrom M, Yeap JS, Alfredson H, Soderman K. Shoulder pain -- a common problem in world-class badminton players. Scand J Med Sci Sports. 2006;16(3):168-173. doi:10.1111/j.1600-0838.2004.00 $\underline{427 . x}$

2. Fahlström M, Söderman K. Decreased shoulder function and pain is common in recreational badminton players. Scand J Med Sci Sports. June 2006. doi:10.1111/j.1600-0838.2006.00562.x

3. Giroto N, Hespanhol JLC, Gomes MRC, Lopes AD. Incidence and risk factors of injuries in Brazilian elite handball players: A prospective cohort study. Scand J Med Sci Sports. 2017;27(2):195-202. doi:10.1111/sm $\underline{\text { s.12636 }}$

4. Moller M, Attermann J, Myklebust G, Wedderkopp $\mathrm{N}$. Injury risk in Danish youth and senior elite handball using a new SMS text messages approach. $\mathrm{Br}$ J Sports Med. 2012;46(7):531-537. doi:10.1136/bjsport s-2012-091022

5. Trakis JE, McHugh MP, Caracciolo PA, Busciacco L, Mullaney M, Nicholas SJ. Muscle strength and range of motion in adolescent pitchers with throwingrelated pain: Implications for injury prevention. $\mathrm{Am} J$ Sports Med. 2008;36(11):2173-2178. doi:10.1177/0363 $\underline{546508319049}$

6. Chard MD, Lachmann SM. Racquet sports patterns of injury presenting to a sports injury clinic. $B M J$. 1987;21:150-153.

7. Moynes DR, Perry J, Antonelli DJ, Jobe FW. Electromyography and motion analysis of the upper extremity in sports. Phys Ther. 1986;66(12):1905-1911. doi:10.1093/ptj/66.12.1905

8. Buckley JP, Kerwin DG. The role of the biceps and triceps brachii during tennis serving. Ergonomics. 1988;31(11):1621-1629. doi:10.1080/00140138808966 $\underline{811}$

9. Ryu RKN, McCormick J, Jobe FW, Moynes DR, Antonelli DJ. An electromyographic analysis of shoulder function in tennis players. Am J Sports Med. 1988;16(5):481-485. doi:10.1177/03635465880160050 $\underline{9}$

10. Fleisig GS, Andrews JR, Dillman CJ, Escamilla RF. Kinetics of baseball pitching with implications about injury mechanisms. Am J Sports Med. 1995;23(2):233-239. doi:10.1177/03635465950230021
11. Richardson AB. Overuse syndromes in baseball, tennis, gymnastics, and swimming. Clin Sports Med. 1983;2(2):379-390. doi:10.1016/s0278-5919(20)3141 $\underline{5-0}$

12. Byram IR, Bushnell BD, Dugger K, Charron K, Harrell FEJ, Noonan TJ. Preseason shoulder strength measurements in professional baseball pitchers: Identifying players at risk for injury. Am J Sports Med. 2010;38(7):1375-1382. doi:10.1177/036354650936040 4

13. Clarsen B, Bahr R, Andersson SH, Munk R, Myklebust G. Reduced glenohumeral rotation, external rotation weakness and scapular dyskinesis are risk factors for shoulder injuries among elite male handball players: A prospective cohort study. $\mathrm{Br} \mathrm{J}$ Sports Med. 2014;48(17):1327-1333. doi:10.1136/bjsp orts-2014-093702

14. Andersson SH, Bahr R, Clarsen B, Myklebust G. Risk factors for overuse shoulder injuries in a mixedsex cohort of 329 elite handball players: Previous findings could not be confirmed. Br J Sports Med. 2017;52(18):1191-1198. doi:10.1136/bjsports-2017-09 $\underline{7648}$

15. Wilk KE, Meister K, Andrews JR. Current concepts in the rehabilitation of the overhead throwing athlete. Am J Sports Med. 2002;30(1):136-151. doi:1 $\underline{0.1177 / 03635465020300011201}$

16. Magnusson SP, Gleim GW, Nicholas JA. Shoulder weakness in professional baseball pitchers. Medicine \& Science in Sports \& Exercise. 1994;26(1):5-9. doi:1 $\underline{0.1249 / 00005768-199401000-00003}$

17. Couppé C, Thorborg K, Hansen M, et al. Shoulder rotational profiles in young healthy elite female and male badminton players. Scand J Med Sci Sports. 2014;24(1):122-128. doi:10.1111/j.1600-0838.2012.01 480.x

18. Hinton RY. Isokinetic evaluation of shoulder rotational strength in high school baseball pitchers. Am J Sports Med. 1988;16(3):274-279. doi:10.1177/036 $\underline{354658801600314}$

19. Wilk KE, Andrews JR, Arrigo CA, Keirns MA, Erber DJ. The strength characteristics of internal and external rotator muscles in professional baseball pitchers. Am J Sports Med. 1993;21(1):61-66. doi:10.1 177/036354659302100111 
20. Wang HK, Cochrane T. Mobility impairment, muscle imbalance, muscle weakness, scapular asymmetry and shoulder injury in elite volleyball athletes. J Sports Med Phys Fitness. 2001;41:403-410.

21. Ng GYF, Lam PCW. A study of antagonist/agonist isokinetic work ratios of shoulder rotators in men who play badminton. J Orthop Sports Phys Ther. 2002;32(8):399-404. doi:10.2519/jospt.2002.32.8.399

22. Bohannon RW. Reference values for extremity muscle strength obtained by hand-held dynamometry from adults aged 20 to 79 years. Arch Phys Med Rehabil. 1997;78(1):26-32. doi:10.1016/s0003-9993(9 7)90005-8

23. Kelsey TW, Li LQ, Mitchell RT, Whelan A, Anderson RA, Wallace WHB. A Validated Age-Related Normative Model for Male Total Testosterone Shows Increasing Variance but No Decline after Age 40 Years. He B, ed. PLoS ONE. 2014;9(10):e109346. doi:1 0.1371/journal.pone.0109346

24. Elmlinger MW, Kühnel W, Wormstall H, et al. Reference intervals for testosterone, androstenedione and SHBG levels in healthy females and males from birth until old age. Clin Lab. 2005;51:625-632.

25. Meister K. Injuries to the shoulder in the throwing athlete. Part one: biomechanics/pathophysiology/ classification of injury. Am J Sports Med. 2000;28(2):265-275. doi:10.1177/03635465000280022 $\underline{301}$

26. Cools AM, Cambier D, Witvrouw EE. Screening the athlete's shoulder for impingement symptoms: A clinical reasoning algorithm for early detection of shoulder pathology. Br J Sports Med. 2008;42(8):628-635. doi:10.1136/bjsm.2008.048074

27. Donatelli R, Ellenbecker TS, Ekedahl SR, Wilkes JS, Kocher K, Adam J. Assessment of shoulder strength in professional baseball pitchers. J Orthop Sports Phys Ther. 2000;30(9):544-551. doi:10.2519/jospt.2000.3 $\underline{0.9 .544}$

28. Hayes K, Walton JR, Szomor ZL, Murrell GAC. Reliability of 3 methods for assessing shoulder strength. J Shoulder Elbow Surg. 2002;11(1):33-39. do i: $10.1067 /$ mse.2002.119852

29. Sullivan SJ, Chesley A, Hebert G, McFaull S, Scullion D. The validity and reliability of hand-held dynamometry in assessing isometric external rotator performance. J Orthop Sports Phys Ther. 1988;10(6):213-217. doi:10.2519/jospt.1988.10.6.213
30. Greenfield BH, Donatelli R, Wooden MJ, Wilkes J. Isokinetic evaluation of shoulder rotational strength between the plane of scapula and the frontal plane. Am J Sports Med. 1990;18(2):124-128. doi:10.1177/036 $\underline{354659001800202}$

31. Hughes RE, Johnson ME, O’Driscoll SW, An K-N. Age-related changes in normal isometric shoulder strength. Am J Sports Med. 1999;27(5):651-657. doi:1 $\underline{0.1177 / 03635465990270051801}$

32. Magnusson SP, Gleim GW, Nicholas JA. Subject variability of shoulder abduction strength testing. Am J Sports Med. 1990;18(4):349-353. doi:10.1177/036354 $\underline{659001800403}$

33. Tyler TF, Nahow RC, Nicholas SJ, McHugh MP. Quantifying shoulder rotation weakness in patients with shoulder impingement. J Shoulder Elbow Surg. 2005;14(6):570-574. doi:10.1016/i.jse.2005.03.003

34. Horvat M, Croce R, Roswal G. Intratester reliability of the Nicholas Manual Muscle Tester on individuals with intellectual disabilities by a tester having minimal experience. Arch Phys Med Rehabil. 1994;75(7):808-811. doi:10.1016/0003-9993(94)9014 $\underline{1-4}$

35. Hopkins WG. Measures of reliability in sports medicine and science. Sports Med. 2000;30(1):1-15. $\underline{\mathrm{d}}$ oi:10.2165/00007256-200030010-00001

36. Glousman R. Electromyographic analysis and its role in the athletic shoulder. Clin Orthop Relat Res. 1993;(288):27-34. doi:10.1097/00003086-19930300 0-00004

37. Cools AM, Palmans T, Johansson FR. Age-related, sport-specific adaptions of the shoulder girdle in elite adolescent tennis players. Journal of athletic training. 2014;49(5):647-653. doi:10.4085/1062-6050-49.3.02

38. Andrews AW, Thomas MW, Bohannon RW. Normative values for isometric muscle force measurements obtained with hand-held dynamometers. Phys ther. 1996;76(3):248-259. doi:1 $\underline{0.1093 / \mathrm{ptj} / 76.3 .248}$

39. Hansen M, Kjaer M. Influence of sex and estrogen on musculotendinous protein turnover at rest and after exercise. Exerc Sport Sci Rev. 2014;42(4):183-192. doi:10.1249/jes.0000000000000026

40. Magnusson SP, Langberg H, Kjaer M. The pathogenesis of tendinopathy: Balancing the response to loading. Nat Rev Rheumatol. 2010;6(5):262-268. doi:10.1038/nrrheum.2010.43 